\title{
CHROMATED COPPER ARSENATE (CCA) TREATED WOOD: DESTINATION OPTIONS FOR WASTES GENERATED AND PERSPECTIVES IN THE DEVELOPMENT OF METHODOLOGIES FOR TOXIC ELEMENTS REMOVAL
}

\author{
FERRARINI, Suzana Frighetto ${ }^{*} ;$ MIRANDA, Luciana Gampert²; MAIA, Sandra Maria ${ }^{3}$ PIRES, \\ Marçal $^{4}$;
}

${ }^{1,4}$ Programa de Pós Graduação em Engenharia e Tecnologia de Materiais (PGETEMA), Pontifícia Universidade Católica do Rio Grande do Sul, Avenida Ipiranga, 6681, 90619-900, Porto Alegre - RS, Brasil

(fone: +55 33534305; fax: +55 33533549)
${ }^{2}$ Faculdade de Química (FAQUI), Pontifícia Universidade Católica do Rio Grande do Sul, Avenida Ipiranga, 6681, 90619-900, Porto Alegre - RS, Brasil

${ }^{3}$ Instituto de Química, Universidade Federal do Rio Grande do Sul, Avenida Bento Gonçalves, 9500, 91501970, Porto Alegre - RS, Brasil

\author{
* Autor correspondente \\ e-mail: suzana.ferrarini@gmail.com
}

Received 29 July 2014; received in revised form 10 September 2014; accepted 15 September 2014

\section{RESUMO}

A madeira vem sendo empregada para diversas funções, sendo uma delas a sua utilização na fabricação de postes para eletrificação e telefonia. Porém, este material possui uma grande propensão à deterioração. Para aumentar a sua durabilidade, utilizam-se algumas alternativas, uma delas é a incorporação de substâncias tóxicas (preservativos) para proteger a madeira de agentes como fungos, bactérias e insetos xilófagos que causam sua deterioração. Atualmente, o preservativo mais utilizado para este fim é o arseniato de cobre cromatado (CCA). Entretanto, quando os postes de madeira tratados com CCA chegam ao final de sua vida útil, tornam-se resíduos perigosos devido à presença de cromo e arsênio. Neste trabalho são apresentadas as principais metodologias para tratamento, opções de destino e disposição adequada desses resíduos, assim como diferentes métodos para remoção dos elementos tóxicos da madeira tratada com CCA.

Palavras-chave: preservativos, contaminação, postes de eucalipto.

\section{ABSTRACT}

The wood has been used for various functions, one of them is the manufacture of poles for electrification and telephony. However, this material has a big propensity to deteriorate. To increase its durability, some alternatives are employed, one of them is the incorporation of toxic substances (preservatives) to protect the wood from agents such as fungi, bacteria and xylophagous insects that cause its decay. Currently, the preservative chromated copper arsenate (CCA) is the most widely used for this purpose. However, when the CCA treated wood poles reach the end of their useful life, they become hazardous waste due to the presence of chromium and arsenic. In this work are presented the main methodologies for treatment, destination options and adequate disposal of these wastes, as well as different methods for toxic elements removal from the CCAtreated wood.

Keywords: preservatives, contamination, eucalyptus poles. 


\section{INTRODUÇÃO}

Por apresentar propriedades como resistência mecânica, facilidade de usinagem, resistência química apreciável, boas propriedades de isolamento térmico e elétrico e diferentes texturas e colorações encontradas, naturalmente (Lepage, 1986), a madeira vem sendo empregada para diversas funções. Um dos principais usos deste material encontra-se na construção civil devido ao consumo de menos energia durante o seu processamento (Lelis, 2001). A utilização de diferentes espécies (tipos) de madeira na fabricação de postes e estruturas para as redes de transmissão e distribuição elétrica é outro grande campo de aplicação, principalmente, em países como Estados Unidos, Canadá, Austrália e África do Sul. No Brasil, este emprego é mais acentuado nos estados do Sul do país (Vidor, 2003).

A origem biológica da madeira, constituída essencialmente por uma matriz relativamente hidrofóbica e de fibras hidrofílicas, a diferencia de outros materiais industriais, porém a grande desvantagem associada a este fato é a propensão à deterioração (Clausen, 1996; Kin e Singh, 2000). Os agentes responsáveis pela deterioração podem ser de natureza física, química ou biológica afetando, diretamente, as propriedades da madeira. O comprometimento de postes de madeira é devido, principalmente, à ação de fungos que causam o apodrecimento $\mathrm{e}$, dependendo da região, a alta umidade pode favorecer a ação dos fungos (Silva, 2006). No Sul do Brasil, por exemplo, este fato é bem mais acentuado do que em outras regiões do Brasil, devido à alta umidade característica da região.

Uma das alternativas encontradas para obter uma maior durabilidade da madeira é o emprego de madeiras com elevada resistência natural aos agentes físicos, químicos e biológicos. Para tanto, considerando que as espécies de alta durabilidade natural são provenientes da floresta tropical, a utilização de espécies alternativas (florestas plantadas) com propriedades semelhantes as das espécies tradicionais é inevitável (Moreschi et al., 2002). Assim, a introdução de alterações químicas permanentes na estrutura dos componentes da madeira ou ainda, a incorporação de substâncias na madeira que the confiram maior resistência, como preservativos, ignífugos e acabamentos superficiais são os meios encontrados para este fim (Silva, 2006). Os preservativos utilizados na proteção da madeira são substâncias químicas tóxicas principalmente aos fungos, bactérias e insetos xilófagos (Lepage, 1986). Na classe dos preservativos, o mais empregado é o arseniato de cobre cromatado (CCA) que é hidrossolúvel, utilizado em diversos países, gerando, conseqüentemente, uma grande quantidade de madeira impregnada com este preservativo (Solo-Gabriele, 1999).

O preservativo CCA, do ponto de vista comercial, é uma excelente alternativa para aumentar a durabilidade da madeira, porém, do ponto de vista ambiental e de saúde pública, o seu uso gera grandes polêmicas por apresentar alto índice de toxicidade. Os componentes arsênio e cromo, presentes no CCA, são metais altamente tóxicos e em vários países há restrições quanto a sua utilização. Essas restrições possuem como base a perda dos componentes do CCA, ao longo do tempo, por lixiviação ou volatilização, acarretando riscos de contaminação ao ser humano e ao meio ambiente (Moreschi et al., 2002). Além dos problemas ambientais e ocupacionais relacionados à produção e utilização da madeira tratada com CCA, um desafio ainda maior, nos dias atuais, é o descarte dos resíduos após a vida útil, por serem considerados perigosos. Os postes empregados na distribuição de energia elétrica e telefonia, após serem retirados de serviço, são exemplos deste tipo de resíduo (Vidor, 2003). Desta forma, o objetivo deste trabalho é fazer uma revisão dos métodos mais empregados para tratamento e disposição de resíduos contendo CCA, com enfoque principal nas metodologias de extração de $\mathrm{Cu}, \mathrm{Cr}$ e As presentes neste preservativo.

\section{ESTIMATIVAS NO USO DE PRESERVATIVOS}

$\mathrm{Na}$ América Latina, o Brasil e o Chile destacam-se como os maiores consumidores de madeira tratada. O Brasil aparece como o maior consumidor com quase $700.000 \mathrm{~m}^{3} \mathrm{e}$, deste total, a grande maioria é tratada com sais de CCA. No ano de 2005 , a produção de madeira foi de cerca de $685.000 \mathrm{~m}^{3}$, destes, $62 \%$ foram empregados para a produção de moirões, $30 \%$ para a produção de postes, $5 \%$ para a produção de dormentes e $3 \%$ para a construção civil (Silva, 
2006). As regiões Sul e Sudeste destacam-se, principalmente, como maiores produtoras de madeira tratada $(90,4 \%)$. Em relação às usinas de tratamento, o CCA representou $80 \%$ do volume utilizado, o borato de cobre cromatado (CCB) juntamente com outros, representaram $15 \%$ e o creosoto $5 \%$. O método de tratamento mais empregado foi o sob pressão em autoclave, representando um total de $84 \%$ (Appel et al, 2006; Silva, 2006).

No estado do Rio Grande do Sul, a quantidade de postes em serviço no ano de 2009 era de 2.888.288. Deste total, os postes de madeira representavam $79 \%$. A substituição prevista para o ano de 2011 em uma das empresas detentoras da concessão de energia era de aproximadamente 40 mil postes. Nesta mesma concessionária de energia, os postes de madeira, na maioria das vezes, são substituídos por postes de concreto, com exceção em locais onde o acesso é difícil (Cruz, 2011). A substituição mássica por postes de concreto tende a aumentar nos próximos anos devido à maior vida útil dos mesmos. Devido a esta substituição, a quantidade de resíduos de madeira tratada com CCA e creosoto* (sem reuso provável) tende a aumentar significativamente no futuro, necessitando cada vez mais de medidas que resolvam ou minimizem este sério problema.

\section{O PRESERVATIVO CCA}

A sigla vem do inglês "Chromated Copper Arsenate", traduzido para o português como arseniato de cobre cromatado, permanecendo a sigla CCA. O registro mais antigo sobre este produto como preservativo de madeira é o pedido de sua patente em 1933 na Índia, e, em 1940, a Bell - System (companhia americana de telefonia) passou a utilizar postes tratados com o produto. Em 1945, o Forest Products Laboratory (Departamento de agricultura americano) passou a realizar trabalhos de campo com o produto. Os resultados obtidos contribuíram fortemente para

$\square^{*} \quad$ preservativo oleossolúvel indicado para o tratamento de madeiras em contato direto com o solo. O creosoto é obtido pelo processo de destilação do alcatrão da hulha (subproduto do processo de obtenção do coque siderúrgico). Possui uma composição química bastante complexa com uma vasta gama de compostos orgânicos associados (Lepage, 1986). a disseminação do CCA, uma vez que as diferenças em relação à durabilidade de postes tratados e sem tratamento foram extremamente grandes (TW Brasil, 2014; TCL 2014).

Ao serem aplicados na madeira, os componentes do sal CCA sofrem uma reação de fixação e tornam-se insolúveis. Esses compostos insolúveis formados protegem a madeira do apodrecimento por fungos, ataque por insetos (cupins ou besouros) e furadores marinhos (moluscos e crustáceos). Entre os produtos submetidos ao tratamento com CCA citam-se dormentes, postes, estruturas para construções residenciais e comerciais, estacas e outros. Além da alta eficiência como preservativo outra vantagem do CCA é manter a madeira limpa e seca, sendo compatível com colas e acabamentos (TW Brasil, 2014).

O CCA é comercializado normalmente sob três tipos distintos: $A, B$ e $C$, cada qual diferindo apenas no teor de cada princípio ativo presente (ABNT, 1985). O CCA tipo C é o mais freqüentemente empregado no tratamento de madeiras. Alguns nomes comerciais comumente empregados no Brasil para este produto são Osmose K-33, AC-40 e Tanalith $®$. A composição do CCA é basicamente obtida por uma mistura de óxidos e a composição de cada óxido varia de fabricante para fabricante, mas, normalmente, emprega-se uma mistura contendo em média $34 \%$ de óxido crômico, $13 \%$ de óxido cúprico, $25 \%$ de pentóxido de arsênio e $28 \%$ de água e inertes.

Cada um dos princípios ativos que fazem parte deste produto possui uma função especifica, ou seja, o cobre possui ação fungicida, o arsênio atua essencialmente como inseticida, porém também complementa a ação fungicida do cobre. O cromo, por sua vez, age como fixador formando complexos insolúveis através de ligações químicas com os componentes da madeira (Jang et al., 2002).

\section{Problemas ocupacionais e não-ocupacionais relacionados ao CCA}

Devido à alta toxicidade da maioria dos constituintes do preservativo a base de CCA, torna-se essencial que os cuidados com o manuseio comecem ainda durante a mistura dos ingredientes nas usinas de tratamento. No Brasil, 
a fabricação deste preservativo é regida pela NBR - 8456 (ABNT, 1985). Abaixo são listados alguns cuidados extremamente importantes, que devem ser levados em consideração, durante o manuseio destes preservativos (TW Brasil, 2014):

- $\quad$ utilização de equipamentos para evitar o contato direto com a pele. Para este fim, empregam-se equipamentos confeccionados com materiais impermeáveis a base de PVC, polietileno e vinil;

- em ambientes com pouca ventilação, onde o preservativo está presente, é necessária a utilização de máscaras adequadas contra seus vapores ou suas soluções;

- $\quad$ águas de lavagem do produto não devem ser jogadas em cursos ou depósitos de água;

- manipuladores do produto, suas soluções ou da madeira recém preservada, não devem ingerir alimentos, bebidas ou cigarros durante o trabalho, bem como manter rigorosa higiene após o contato com os mesmos e, cuidados minuciosos com roupa que apresente sinais de contaminação;

- é necessário guardar as roupas e os EPI's de uso diário separados de roupas e calçados de uso pessoal.

Segundo Vidor (2003), alguns problemas ocasionados pela manipulação inadequada do preservativo podem ser citados:

- danos à pele, olhos e mucosas: devido à alta irritabilidade e corrosividade e o contato do produto com essas vias de exposição poderá ocasionar queimaduras severas. A exposição dérmica repetida poderá resultar em úlceras e dermatites;

- a ingestão, por ser altamente tóxico, causa gastroenterite, dor no esôfago e estômago além de oliguria ou anuria;

- a inalação, por ser altamente irritante, poderá resultar em pneumonia química.

Devido à utilização de madeira tratada com CCA para a fabricação de várias estruturas residenciais, entre elas estruturas para recreação, existem vários estudos relatando a contaminação de crianças pelos componentes do preservativo (Hamula et al., 2006; Hemond e Solo-Gabriele, 2004; Kwon et al., 2004; Reed et al., 1999). Em um destes estudos (Hamula et al.,
2006), foi medida a concentração de cromo nas mãos de crianças após as mesmas terem brincado em playground feito com madeira submetida a este tipo de tratamento. Para a coleta das amostras as mãos das crianças foram lavadas por um período de um minuto com água deionizada, após o término do contato com o playground, sendo as águas de lavagem coletadas diretamente em sacos plásticos com vedação apropriada. Os resultados do estudo mostraram que as crianças apresentaram em suas mãos, duas vezes mais cromo após brincarem em playground feito com madeira tratada, do que quando brincaram em playground sem tratamento nenhum. Este aumento, provavelmente, estaria relacionado com 0 contato direto das crianças com a madeira tratada com CCA. Segundo os autores, os resultados obtidos também poderiam estar relacionados com o contato direto das crianças com a areia contaminada com cromo nos arredores do playground. No entanto, esta suposição tornou-se menos provável, uma vez que quase todo o cromo e seus compostos são insolúveis na areia ou solo.

\section{Redução na utilização do CCA devido a restrições na legislação}

No Brasil, ainda não existem restrições quanto à utilização do CCA. Na Europa, no entanto, o emprego deste tipo de preservativo, para algumas finalidades, foi proibido. Em 2004, países como a Suécia e Dinamarca proibiram o uso de madeira tratada com CCA em algumas aplicações especiais como, por exemplo, usos domiciliares. Nos Estados Unidos a Agência de Proteção Ambiental (EPA) declarou, em 2003, que as indústrias decidiram voluntariamente não mais empregar madeira tratada com CCA para objetos de uso residencial. Essa restrição inclui estruturas de recreação, mesas, madeiras para jardinagem e paisagismo, cercas residenciais, passarelas e plataformas, sendo devida ao alto risco de contato com os seres humanos. Essa decisão, provavelmente, estaria relacionada aos estudos discutidos nos parágrafos anteriores onde foi relatada a contaminação ocasionada pelo contato direto com a madeira tratada com CCA, empregada na confecção de estruturas domiciliares. No entanto, não existem restrições quanto ao emprego do produto para fins rurais $\mathrm{e}$ industriais (Moreschi et al., 2002). 
Classificação dos resíduos de madeira tratada com CCA

Há diferentes interpretações no que diz respeito à classificação dos resíduos resultantes dos processos de tratamento da madeira. Em alguns países europeus esses resíduos recebem a classificação de perigosos e, por este motivo, a sua disposição final segue legislação rigorosa (Helsen e Van den Bulk, 2005). Entretanto, em outros países, como Brasil, eles ainda não despertaram atenção necessária e são tratados da mesma forma que os demais, não sendo classificados como perigosos (ABNT, 2004). Segundo a norma NBR 10.004 (2004) apenas os efluentes líquidos e resíduos originados do processo de preservação da madeira, provenientes de plantas que utilizam preservativos inorgânicos contendo arsênio ou cromo, são classificados como resíduos perigosos.

Para ser classificado como Resíduo Classe I (Perigoso) o resíduo deve apresentar características comprovadas de periculosidade, reatividade, corrosividade, toxicidade, inflamabilidade, patogenicidade ou estar contido em anexos específicos da NBR 10004. Dentre estas características, o resíduo de madeira tratada com CCA pode ser considerado perigoso em relação à toxicidade. No entanto, um resíduo é considerado tóxico se uma amostra representativa dele apresentar uma das seguintes propriedades (ABNT, 2004):

- $\quad$ quando o extrato obtido desta amostra contiver qualquer um dos contaminantes em concentrações superiores aos valores constantes no anexo $F$ (da referida norma). Neste caso, o resíduo deve ser caracterizado como tóxico com base no ensaio de lixiviação

- possuir uma ou mais substâncias constantes no anexo C (da referida norma) e apresentar toxicidade

- $\quad$ ser constituído por restos de embalagens contaminadas com substâncias constantes nos anexos $\mathrm{D}$ ou $\mathrm{E}$ (da referida norma)

- resultar de derramamentos ou de produtos fora de especificação ou do prazo de validade que contenham quaisquer substâncias constantes nos anexos D ou $E$ (da referida norma)

- $\quad$ ser comprovadamente letal ao homem
- possuir substância em concentração comprovadamente letal ao homem ou estudos do resíduo que demonstrem uma DL50 (dose letal) oral para ratos menor que $50 \mathrm{mg} / \mathrm{kg}$ ou CL50 (concentração letal), inalação para ratos menor que $2 \mathrm{mg} / \mathrm{L}$ ou uma DL50 dérmica para coelhos menor que $200 \mathrm{mg} \mathrm{kg}^{-1}$.

As normas de classificação de resíduos sólidos são extremamente trabalhosas, envolvendo várias etapas e um longo período de tempo. Provavelmente, por este motivo, na literatura brasileira encontraram-se poucos trabalhos que relatam a classificação dos resíduos de madeira tratada com CCA (Ferrarini et al., 2012; Silva, 2008). Segundo Ferrarini et al. (2012) os valores de concentrações obtidas para As, após teste de lixiviação em resíduos de postes de madeira tratada com CCA, variaram de 2,7 a 9,2 $\mathrm{mg} \mathrm{L}^{-1}$ excedendo assim, em todas as amostras avaliadas (sete amostras), a concentração de $1 \mathrm{mg} \mathrm{L}^{-1}$ estipulada pela ABNT NBR 10004. Com base em propriedades de toxicidade, estes dados significam que este material pode ser considerado resíduo classe I Perigoso se a regulamentação da ABNT NBR 10004 for aplicada. Os resultados obtidos por Silva (2008) em duas espécies diferentes de madeira tratada com CCA, também classificam esse tipo de resíduo como perigoso. Para As os valores de concentração obtidos variaram de 16,5 a $32,0 \mathrm{mg} \mathrm{L}^{-1}$ já, para $\mathrm{Cr}$ variaram de 7,0 a $14,7 \mathrm{mg} \mathrm{L}^{-1}$. Com base nestes trabalhos, esses resíduos não podem ser descartados juntamente com os demais sendo necessário, por exemplo, o emprego de metodologias de remoção dos elementos tóxicos presentes nos mesmos.

\section{OPÇÕES DE DESTINO PARA OS RESÍDUOS DE MADEIRA TRATADA COM CCA}

Ao se tratar do destino dado aos resíduos provenientes de madeira tratada com CCA, alguns fatores importantes deverão ser levados em consideração e esses fatores, normalmente, diferem de região para região. Na Europa, por exemplo, grande parte dos resíduos de madeira tratada é incinerada, enquanto que na América do Norte, quase todos esses resíduos são enviados para aterros sanitários (Helsen e Van den Bulk, 2005). As alternativas adotadas para os resíduos em questão estão relacionadas abaixo:

- $\quad$ minimização ou eliminação 


$$
\begin{array}{ll}
\text { - } & \text { reutilização } \\
\text { - } & \text { reciclagem } \\
\text { - } & \text { tratamento ou destruição } \\
& \text { disposição final }
\end{array}
$$

Cada uma delas tem suas vantagens $e$ desvantagens, sendo apresentadas nos tópicos seguintes.

\section{Minimização ou eliminação}

A minimização ou eliminação dos resíduos inclui a utilização de materiais com estruturas alternativas, preservativos químicos alternativos, tratamentos suplementares ou retrata mento químico.

Entre os materiais de estruturas alternativas, cita-se o emprego de madeiras com maior resistência natural ou a utilização de materiais como concreto, aço, alumínio e fibra de vidro. Para tanto, serão necessárias avaliações completas relacionadas ao ciclo de vida útil destes materiais. Uma desvantagem relacionada ao emprego de madeiras com maior resistência é o alto custo envolvido, além de um maior tempo de crescimento se comparado às espécies menos resistentes (Helsen e Van den Bulk, 2005; ABNT, 2004; Ferrarini et al., 2012; Silva, 2008; Solo-Gabriele e Townsend, 1999; Cooper e Associados, 2001).

Entre os preservativos químicos alternativos ao CCA, alguns produtos poderão ser empregados para aplicações ao ar livre e para uso com contato humano limitado (uma vez que possuem uma maior toxicidade que o CCA). Nesta classe, podem ser citados, o creosoto, o pentaclorofenol e o naftanato de cobre. Esta utilização irá depender da legislação local. Apesar de apresentarem altos riscos ambientais, esses preservativos possuem a vantagem de não produzirem resíduos de combustão com elevados níveis de arsênio e cromo (Helsen e Van den Bulk, 2005; ABNT, 2004; Ferrarini et al., 2012; Silva, 2008; Solo-Gabriele e Townsend, 1999; Cooper e Associados, 2001).

A classe de tratamentos suplementares inclui, por exemplo, o emprego de repelentes de água ou coberturas plásticas em produtos de madeira já tratados com CCA. Estes complementos ajudariam a manter o CCA dentro da madeira, aumentando assim, a sua vida útil e precoce substituição, além de diminuir o volume de resíduos gerados (Solo-Gabriele e Townsend, 1999; Cooper e Associados, 2001).

Um método que também vem sendo empregado como um meio promissor no aumento da vida útil da madeira é o retratamento químico. Neste processo ocorre a reaplicação de algum tipo de preservativo apenas na área em processo de degradação que normalmente é próxima do solo. Esses produtos são destinados ao tratamento interno e externo dos postes. Existem dois métodos para o retratamento, um externo que utiliza uma bandagem e um interno que utiliza bastonetes (Lepage, 1986). No Brasil, no período de 1980 a 1990, utilizou-se bandagem a base de uma mistura de creosoto com CCA (Osmocreo). Esse produto não é mais comercializado e sua eficácia não foi comprovada. Mais recentemente, foram introduzidos no mercado produtos de origem australiana (já utilizados neste país), a base de boro e/ou flúor empregados para o retratamento interno e externo, ambos os processos podem ser visualizados na Figura 1. Um estudo pioneiro no Brasil sobre o uso destes preservativos em moirões instalados em áreas de testes controladas (Vidor, 2003), sinalizou um provável aumento do tempo de vida útil dessas estruturas. Entretanto, a comprovação da eficácia do retratamento, em condições reais (p.ex.: postes em serviço), bem como a possível migração do flúor para o solo e águas adjacentes a madeira tratada, devem ser melhores avaliadas. 


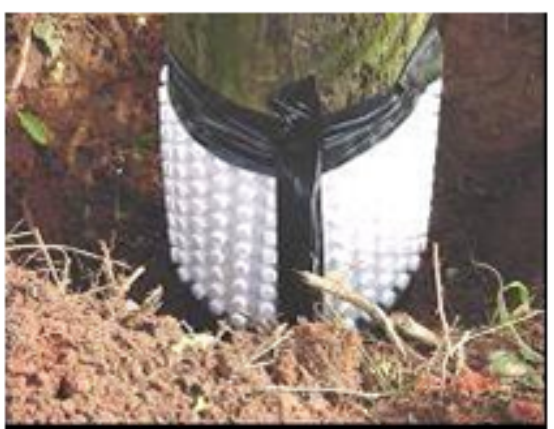

$\mathrm{a}$

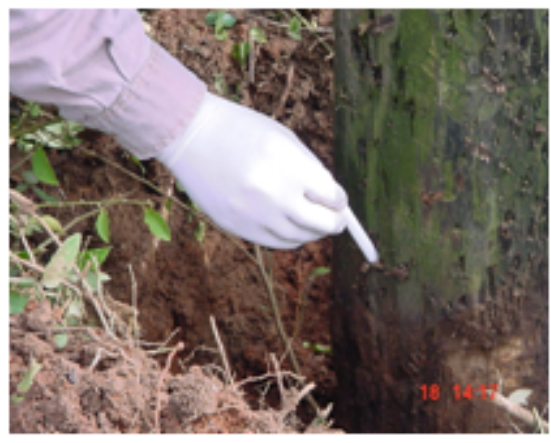

b

Figura 1. Retratamento de postes: a) aplicação de bandagem fixa (preservativo a base de boro e flúor) b) aplicação de bastonete (preservativo a base de boro). Fonte: Vidor, 2003.

\section{Reutilização}

As aplicações para a reutilização destes resíduos incluem o emprego em cercas para jardins, pilares para muros e também como matéria-prima para outros produtos, porém existem várias desvantagens associadas a esses usos (Helsen e Van den Bulk, 2005):

- $\quad$ os resíduos de madeira são normalmente grandes e volumosos tornando difícil o transporte e, com a diminuição de tamanho dos mesmos, podem ser gerados resíduos de serragem contaminados;

- possível contaminação por objetos impregnados na madeira como placas, parafusos e outros do gênero. Para resolver este problema, seria necessário o desmonte, ocasionando um custo elevado;

- de forma geral, altos custos envolvidos nos processos de manipulação, classificação, transporte e estocagem.

A reutilização de postes de madeira após serem retirados de serviço pelas concessionárias de energia é, provavelmente, o procedimento mais adotado em nosso país, porém além das desvantagens citadas anteriormente, um dos problemas que merece bastante destaque, é a falta de controle por parte dessas empresas em relação ao reuso dos postes. Através de empresas terceirizadas contratadas pelas concessionárias de energia, os postes chegam às mãos de produtores rurais e, estes possuem pouca ou nenhuma informação em relação à periculosidade dos mesmos.

Antes de serem repassados aos produtores rurais, os postes retirados de serviço ficam expostos ao ar livre, não havendo preocupação em relação à contaminação do solo pela lixiviação dos elementos tóxicos, presentes neste material. A Figura 2 mostra esta realidade. Este sério problema só será minimizado quando existir por parte destas empresas uma maior consciência em relação à toxicidade apresentada por este tipo de resíduo.
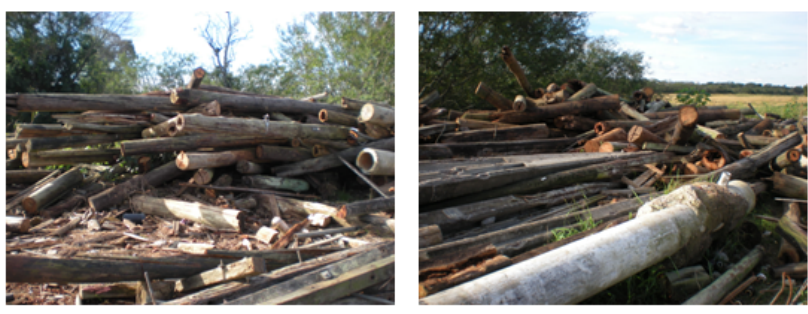

Figura 2. Postes tratados com CCA após serem retirados de serviço. Fonte: Ferrarini, 2012.

\section{Disposição Final}

Umas das opções para os resíduos de madeira tratada é a incineração direta dos mesmos e, posteriormente, a disposição adequada das cinzas resultantes deste processo. Se não houver restrições na legislação local, as mesmas poderão ser colocadas diretamente em aterros.

Durante a incineração, os resíduos poderão ser usados como geradores de energia ou ainda, como combustíveis em certas operações industriais como, por exemplo, em forno de cimento. As vantagens do emprego destes resíduos na geração de energia, ou como combustíveis, baseiam-se no fato de que há menos dependência pelos combustíveis fósseis e também há a redução considerável do volume destes antes da remoção, por exemplo, para um 
aterro. Porém, há grandes desvantagens associadas a esta forma de disposição dos resíduos da madeira tratada, ou seja, emissões atmosféricas potenciais e alta concentração de metais na cinza resultante do processo de incineração (Solo-Gabriele e Townsend, 1999; Cooper e Associados, 2001).

Quando incinerados, boa parte do cobre e cromo presentes nos resíduos fica retida na cinza, restringindo fortemente as alternativas de se empregar este resíduo para fins de reciclagem. Se durante 0 processo de incineração forem empregadas temperaturas acima de $300{ }^{\circ} \mathrm{C}$, quantidades significativas de arsênio poderão ser volatilizadas. No entanto, essas quantidades podem aumentar de 40 a $60 \%$ ao se utilizarem temperaturas na faixa de 750 a $1300{ }^{\circ} \mathrm{C}$. No entanto, muitas usinas de incineração possuem dispositivos de controle de poluição de ar, os quais conseguem recapturar uma fração significante dos metais volatilizados (Hirata et al,. 1993).

Um processo térmico que merece ser destacado, cujo uso está crescendo bastante é o processo "Chartherm". Este processo foi desenvolvido em Bordeaux (França). Atualmente o mesmo já não se encontra em escala piloto e é usado industrialmente. Três etapas principais compõem o processo (Lepage, 2010; Chartherm, 2013):

1. passagem da madeira pelo triturador

2. tratamento térmico à baixa temperatura ("Charterização")

3. separação

Na primeira etapa, a madeira é reduzida em pedaços menores (com comprimento de até $5 \mathrm{~cm}$ ) para a introdução no processador térmico. $\mathrm{Na}$ etapa seguinte, o processo térmico é conduzido em uma coluna que é mantida em regime contínuo, seguindo uma destilação pirolítica escalonada com dois fluxos operando em contra corrente. Na última etapa, os produtos sólidos saem pela base da coluna e são levados para uma centrífuga pneumática onde os minerais são separados do carbono. O produto final é carbono inerte com granulometria inferior a $15 \mu \mathrm{m}$. Este produto serve para várias aplicações industriais, seja na forma de carvão ativo, ou negro de fumo (pneus e elastômeros). Segundo defensores do processo, cada tonelada de madeira tratada com CCA produz $280 \mathrm{~kg}$ de carbono e $50 \mathrm{~kg}$ de resíduos que contêm praticamente todos os metais presentes no produto inicial, ou seja, a perda para o meio ambiente é praticamente nula (Lepage, 2010; Chartherm, 2013). Um esquema deste processo está apresentado na figura 3.

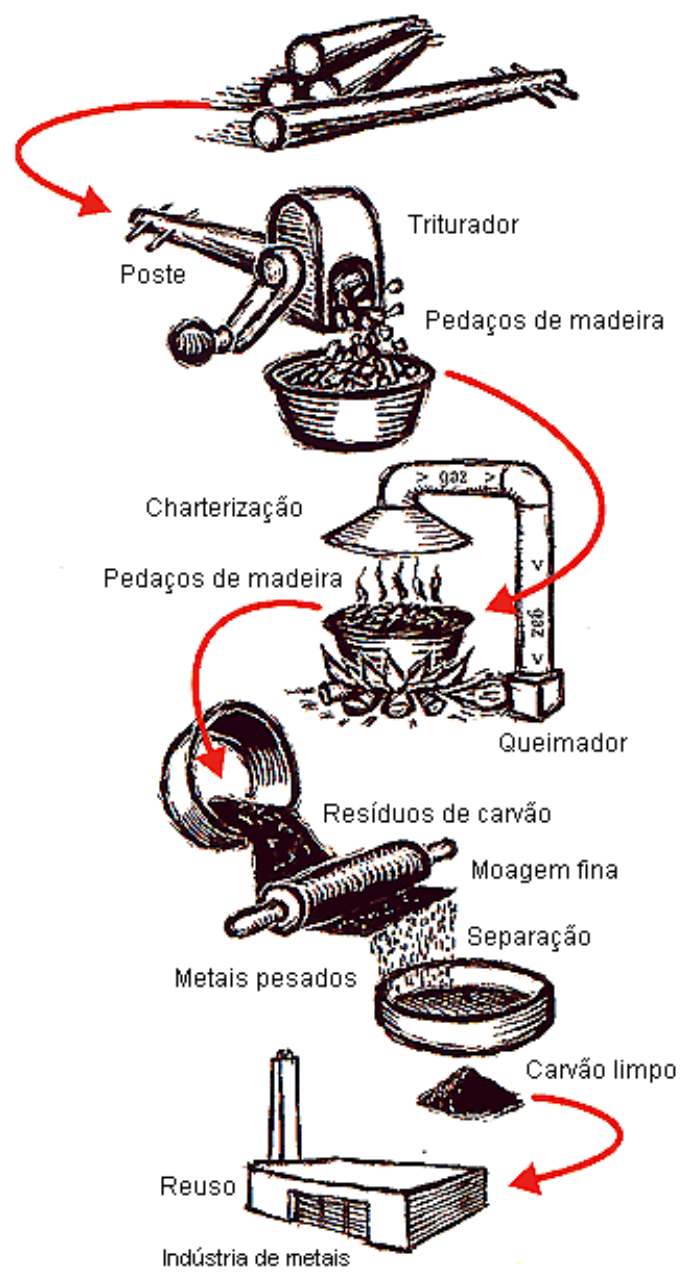

Figura 3. Esquema representativo com o princípio de reciclagem dos postes de madeira. Adaptação: http://www.chartherm.com/english/ chartherm/index.html. Acesso Outubro de 2013.

Em alguns países, como Indonésia e Alemanha, a disposição direta de madeira tratada em aterros é proibida. Nos Estados Unidos, a disposição de madeira tratada com CCA em aterros é regulada com base nas características de lixiviação da madeira, sendo determinada por protocolos padrão de lixiviação (Solo-Gabriele e Townsend, 1999). No Brasil não há nenhuma norma específica relacionada à disposição dos resíduos de madeira tratada com CCA. O único registro relacionado a resíduos de 
madeira encontra-se na resolução 307 do Conselho Nacional do Meio Ambiente CONAMA, do ano de 2002 (CONAMA, 2002). Segundo esta resolução, a fração madeira dos resíduos da construção civil é classificada como Classe $\mathrm{B}$, isto é, resíduos recicláveis para outras destinações, tais como: plásticos, papel/papelão, metais, vidros, madeiras e outros. $\mathrm{O}$ artigo 10 , da mesma resolução, faz referência ao destino dos mesmos, ou seja, deverão ser reutilizados, reciclados ou encaminhados a áreas de armazenamento temporário, sendo dispostos de modo a permitir a sua utilização ou reciclagem futura. Observa-se na referida resolução que não há distinção entre a madeira tratada e madeira sem tratamento. Desta forma, madeiras impregnadas com produtos perigosos como o CCA, pentaclorofenol e creosoto podem ser dispostas em aterros comuns.

Devido às constatações acima, em 2009, o Conselho Brasileiro de Construção Sustentável - CBCS (CBCS, 2009) encaminhou ao Ministério do Meio Ambiente uma proposta de correção da resolução 307 , sugerindo a reclassificação da madeira industrializada para classe D. Os resíduos classificados como classe $D$ são os resíduos perigosos oriundos do processo de construção, tais como: tintas, solventes, óleos e outros, ou aqueles contaminados oriundos de demolições, reformas e reparos de clínicas radiológicas, instalações industriais e outros (CBCS, 2009). Mesmo sendo reclassificados para esta nova classe, seria necessário ainda acrescentar um item referente à madeira tratada. Desta forma, o destino para esta classe seria o armazenamento, transporte, reutilização e destino em conformidade com as normas técnicas específicas.

\section{Reciclagem e tratamento}

Com exceção da disposição final, cabe destacar que todas as opções apresentadas até agora, neste trabalho, não eliminam os resíduos de madeira tratada com CCA (postes de madeira), apenas prolongam a vida útil dos postes, retardando, assim, sua substituição. Como esperado, o volume desses resíduos tende aumentar significativamente no futuro. Desta forma, seria imprescindível o desenvolvimento de metodologias viáveis, rápidas, seguras e econômicas para resolver este sério problema. Neste caso, a reciclagem de resíduos tratados com CCA surge como um meio promissor.

A reciclagem consiste, por exemplo, na recuperação de porções não tratadas da madeira para depois empregá-las para outros propósitos. Dependendo do fim específico para qual se destina torna-se necessário, primeiramente, considerar tecnologias de remoção do CCA da madeira tratada, uma vez que os componentes do preservativo (cobre, cromo e arsênio) poderão ser lixiviados durante a reutilização da mesma (Solo-Gabriele e Townsend, 1999). Entre as tecnologias de tratamento mais freqüentemente empregadas estão a biodegradação através de fungos e a extração dos componentes do CCA através de meios químicos e eletrolíticos. Estes tratamentos são alternativas promissoras para os resíduos de madeira tratada com CCA, sendo apresentados a seguir.

\section{TRATAMENTOS DE REMOÇÃO DE COBRE, CROMO E ARSÊNIO EM RESÍDUOS DE MADEIRA TRATADA COM CCA}

\section{Extração química}

A extração ácida é uma das metodologias mais empregada para a extração dos componentes presentes nos resíduos da madeira tratada com CCA. Ao submeter esses resíduos aos processos de extração ácida pode ocorrer a reversão das reações de fixação, por meio da conversão dos elementos do CCA para suas formas solúveis em água (Clausen et al,. 2001). Pesquisas mostram que os reagentes mais empregados para a remoção de $\mathrm{Cu}, \mathrm{Cr}$ e As, nesse tipo de resíduo, são os ácidos orgânicos, minerais e agentes complexantes. Entre os ácidos orgânicos empregados como agentes de extração, estão os ácidos cítrico, acético, fórmico, oxálico, fumárico, tartárico, glucônico e maleico e, entre os ácidos minerais, estão os ácidos sulfúrico, clorídrico, nítrico e fosfórico. $\mathrm{Na}$ classe dos agentes complexantes citam-se o ácido etilenodiaminotetracético (EDTA) e o ácido nitrilotriacético (NTA) (Kartal, 2003). Além da utilização de ácidos e agentes complexantes, polímeros naturais e fungos, também vem sendo empregados com o objetivo de remoção dos elementos. 
Nem sempre a utilização de apenas um dos reagentes citados acima consegue ser eficiente na remoção dos três elementos presentes no CCA. Cromo encontra-se fortemente ligado à lignina presente na matriz de madeira e os sais do preservativo CCA possuem uma baixa solubilidade. Além disso, a maioria dos reagentes empregados para este fim provoca a decomposição dos componentes da madeira durante a exposição ácida. Assim, a metodologia deve ser desenvolvida e aperfeiçoada para que haja uma extração efetiva dos elementos de interesse. Neste caso, os ácidos utilizados devem, necessariamente (Kakitani et al,. 2006):

- quebrar a forte ligação entre o cromo e a lignina;

- dissolver moderadamente os sais de CCA;

- manter o pH em torno de 5,0 uma vez que em $\mathrm{pH}$ acima deste valor $\mathrm{Cu}$ (II) e $\mathrm{Cr}$ (III) precipitam como hidróxidos de metais insolúveis;

Alguns reagentes empregados na remoção de $\mathrm{Cu}, \mathrm{Cr}$ e As, bem como suas propriedades, são discutidos abaixo.

\section{Ácidos orgânicos}

Um dos agentes extratores que mais vem sendo empregado para a remoção de $\mathrm{Cu}, \mathrm{Cr}$ e As de resíduos de madeira tratada com CCA é o ácido oxálico. Este ácido orgânico reage com o elemento cromo, presente em sua forma insolúvel. O composto formado na reação é o oxalato de cromo, extremamente solúvel, sendo, assim, lixiviado da madeira. Em contrapartida, o ácido oxálico reage com o cobre formando um composto insolúvel que é o oxalato de cobre e, mesmo após vários processos de lixiviação, este composto não sofre alteração. No entanto, para reverter esta reação, a adição de amônia proporciona a lixiviação, uma vez que este reagente solubiliza o oxalato de cobre, pela alcalinização do meio (Humar et al,. 2004).

Kakitani et al. (2006) fizeram o uso de uma solução aquosa de ácido oxálico para extração de $\mathrm{Cu}, \mathrm{Cr}$ e As no mesmo tipo de amostra. Com o propósito de elevar o pH para uma condição alcalina, foi empregado o hidróxido de sódio. Além de elevar o pH da solução, este reagente também favoreceu a dissolução do oxalato de cobre evitando, assim, a adição de qualquer outro tipo de reagente.

Isosaari et al. (2010) empregaram o mesmo ácido para remover $\mathrm{Cu}, \mathrm{Cr}$ e As de postes de madeira tratada com CCA porém, empregaram extrações sequenciais em conjunto com processos eletrocinéticos. Sob as melhores condições foi possível remover $67 \%$ de $\mathrm{Cu}, 64 \%$ de $\mathrm{Cr}$ e $81 \%$ de As.

Outro ácido orgânico empregado na remoção de $\mathrm{Cu}, \mathrm{Cr}$ e As é o ácido cítrico. Shiau et al. (2000) empregaram este reagente e compararam a sua eficiência com outros reagentes (ácido acético e ácido sulfúrico). Nas condições estudadas pelos autores, o ácido cítrico mostrou-se o mais eficiente sendo possível obter remoções de $76 \%$, $8 \%$ e $45 \%$ para $\mathrm{Cu}, \mathrm{Cr}$ e As, respectivamente.

Em outro estudo (Sierra-Alvarez, 2009) foi possível obter remoções ainda maiores com o uso deste mesmo reagente. As remoções para $\mathrm{Cu}, \mathrm{Cr}$ e As atingiram $87 \%, 80 \%$ e $100 \%$, respectivamente.

\section{Ácidos inorgânicos}

Os ácidos inorgânicos mais comumente utilizados na remoção dos elementos tóxicos dos resíduos de madeira tratada com CCA são o ácido nítrico e o ácido sulfúrico (Moghaddam e Mulligan, 2008; Janin et al,. 2009a). Este último é o mais empregado por ser de baixo custo. A escolha do reagente é uma questão extremamente importante pois, como se tem uma grande quantidade de resíduos, será necessário um grande volume de extrator.

Janin et al. (2009a) otimizaram um processo de lixiviação de $\mathrm{Cu}, \mathrm{Cr}$ e As de madeiras tratadas com CCA no intuito de obter um sistema economicamente viável. Neste sentido, vários parâmetros foram estudados pelos autores, entre eles: extrator, concentração do extrator, razão sólido/liquido, temperatura do meio reacional, tempo de reação e tamanho de partícula. O reagente que demonstrou maior eficiência de remoção foi o ácido sulfúrico em uma concentração de 0,1 M sob uma temperatura de $75^{\circ} \mathrm{C}$ e uma razão de sólidos de $15 \%$. O processo foi conduzido em 3 etapas de extração de 2 horas. Os percentuais de remoção para $\mathrm{Cu}, \mathrm{Cr}$ e As nessas condições chegaram a 
$99 \%, 91 \%$ e $99 \%$, respectivamente.

Esse mesmo grupo de pesquisa vem constantemente desenvolvendo novas metodologias para remoção de elementos tóxicos de madeira tratada (Coudert et al., 2014), Janin et al., 2012a), Janin et al., 2012b), Janin et al., 2012c), Janin et al., 2011), Janin et al., 2009b), Janin et al., 2009c). As pesquisas do grupo envolvem diferentes amostras (madeiras com diferentes teores iniciais de CCA e diferentes tempos entre o tratamento preservante e a remediação) (Goudert et al., 2014), testes em escala piloto (Janin et al., 2012a), testes com outros preservativos a base de cobre (Janin et al., 2012b, Janin et al., 2011) e tratamento/recuperação/re-uso do efluente gerado no processo de descontaminação (Janin et al., 2012c, Janin et al., 2009b),

\section{Agentes complexantes}

Nesta classe de reagentes o ácido etilenodiaminotetracético - EDTA se destaca na imobilização e remoção de $\mathrm{Cu}, \mathrm{Cr}$ e As (Clausen et al., 2001). O EDTA é um agente complexante que forma complexos estáveis (quelatos) com a maioria dos metais. A estrutura do EDTA é composta por dois grupos amino e quatro grupos carboxílicos, conferindo ao composto a capacidade de fazer ligações com íons metálicos através de seis sítios, sendo classificado como um ligante hexadentado. Os complexos formados são solúveis e, por isso, os metais podem ser removidos de superfícies contaminadas (Thomas et al., 1998).

A propriedade do EDTA de se ligar fortemente em íons metálicos através da formação de complexos estáveis pode também ser utilizada para dois processos interligados, ou seja, processos de dessorção de íons adsorvidos e processos de dissolução de compostos metálicos insolúveis (Papassiopi et al., 1999). Deste modo, há vários estudos voltados ao emprego de complexantes como o EDTA na remediação e extração de metais de solos contaminados por diferentes fontes, incluindo usinas de preservação de madeira, operações metalúrgicas, resíduos industriais e emissões veiculares (Wasay et al,. 2001).

A utilização do EDTA para extração de $\mathrm{Cu}, \mathrm{Cr}$ e As em resíduos de madeira tratada também merece destaque. Kartal et al., 2003) fizeram um estudo com este reagente em diferentes tipos amostras de madeira, ou seja, amostras em formato de bloco, em formato de cavaco e moída. Os resultados obtidos para $\mathrm{Cu}$ foram bastante efetivos nos três tipos de amostras devido às propriedades complexantes do EDTA. Nas amostras moídas, a remoção dos três elementos de interesse foi três vezes menor do que no restante das amostras. Nas amostras em formato de cavaco três a cinco vezes mais $\mathrm{Cu}$ foi removido do que As e Cr. A menor remoção de $\mathrm{Cr}$ e As está relacionada ao complexo estável formado com a lignina.

Pesquisas mostram que 0 ácido nitrilotriacético (NTA) apresenta eficiência análoga a do EDTA na extração dos referidos elementos, possivelmente, por apresentar propriedades semelhantes a este reagente (Kakitani et al,. 2006; Kartal e Kose, 2003). Porém, devido ao elevado custo, quando comparado ao EDTA o NTA é menos utilizado.

Outro agente que vem apresentando moderada eficiência na remoção de $\mathrm{Cu}, \mathrm{Cr}$ e As dos resíduos de madeira tratada com CCA é o ácido etilenodiaminodisuccínico - EDDS (Chang et al., 2013).

\section{Polímeros naturais}

Materiais naturais disponíveis em grandes quantidades e vários resíduos de produtos agrícolas e de pesca podem ser considerados como tecnologias efetivas e alternativas para a remediação de resíduos de madeira tratada. Esses materiais possuem a capacidade de reter elementos tóxicos de soluções aquosas, além de serem potencias adsorventes de baixo custo. Entre eles, a quitina e a quitosana se destacam (Kartal e Imamura, 2005).

A quitina é um polímero natural extraído da casca de crustáceos assim como pitu, caranguejo, insetos e camarão. Por outro lado, a quitosana é um polímero extraído da quitina utilizando um procedimento de deacetilação alcalina produzindo um heteropolímero. Esses dois polímeros naturais possuem grande interesse comercial por apresentarem uma percentagem de nitrogênio de $7 \%$. Os grupos amina e hidroxílicos presentes em suas estruturas químicas atuam como posições de complexação dos íons metálicos. Entre as 
propriedades apresentadas por estes compostos destacam-se a biocompatibilidade, a biodegradabilidade, a não toxicidade e a propriedade de adsorver metais (Kartal e Imamura, 2005).

Kartal e Imamura (2005) utilizaram os referidos polímeros na tentativa de remover $\mathrm{Cu}$, $\mathrm{Cr}$ e As dos resíduos de madeira tratada com CCA. Os resultados desta pesquisa com a utilização da quitina mostram que, nas melhores condições, foi possível obter percentagens de remoção de $74 \%, 62 \%$ e $63 \%$ para $\mathrm{Cu}, \mathrm{Cr}$ e As, respectivamente. Com a quitosana, no entanto, as remoções foram menos efetivas, com percentagens de $57 \%, 43 \%$ e $30 \%$ para $\mathrm{Cu}, \mathrm{Cr}$ e As, respectivamente.

\section{Fungos}

Através de processos biotecnológicos alguns microorganismos, assim como fungos, são capazes de liberar ácidos orgânicos em diferentes concentrações dentro de meios de cultura. Deste modo, os ácidos liberados pelos fungos podem ser utilizados na remediação de resíduos contendo os elementos $\mathrm{Cu}, \mathrm{Cr}$ e As. Entre os ácidos que podem ser produzidos nos meios de cultura estão os ácidos oxálico, cítrico e glucônico. Várias espécies de fungos foram efetivas na remoção de metais pesados tóxicos de soluções aquosas, sendo por meio de processos de biosorção ou processos de bioacumulação, diretamente pela ação de grupos funcionais localizados na superfície externa da célula dos fungos (Kartal e Imamura, 2005).

Kartal et al. (2006) relataram um estudo no qual foram utilizadas dez diferentes espécies de fungos com o objetivo de avaliar a habilidade dos mesmos na produção de ácido oxálico para posterior remediação de madeira tratada com CCA. Os resultados mostraram que para o metal $\mathrm{Cu}$, pode-se chegar a uma percentagem de remoção de até $90 \%$ com algumas espécies de fungos. No entanto, o elemento $\mathrm{Cr}$, mostrou-se mais resistente à remoção pela ação dos fungos, sendo que a percentagem de remoção utilizando diferentes espécies variou de 20 a $50 \%$. Para o elemento As, dependendo da espécie de fungo empregada, houve uma percentagem variada de remoção. Algumas espécies possibilitaram uma remoção de até $90 \%$ enquanto outras apenas $30 \%$.

\section{Remediação eletrodialítica}

O método de remediação eletrodialítica que emprega uma corrente direta de baixa voltagem como agente de limpeza, é uma combinação de remediação eletrocinética com eletrodiálise. $\mathrm{O}$ princípio de funcionamento deste método é mostrado na Figura 4.

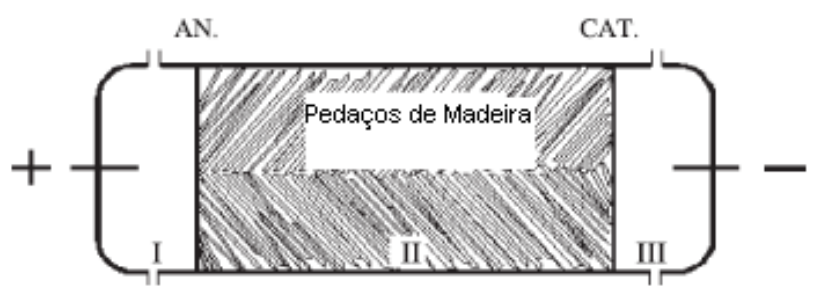

Figura 4. Princípio da remediação eletrolítica. $\mathrm{AN}=$ membrana de troca aniônica. CAT = membrana de troca catiônica. Adaptação: Pedersen, 2005.

O material poluído é colocado em um compartimento (compartimento II). Os compartimentos II e III são compartimentos que contém os eletrodos inertes e onde circulam soluções de eletrólitos. Os compartimentos, onde estão os eletrodos, são separados do material poluído por uma membrana de troca iônica. No lado onde se encontra o ânodo usa-se uma membrana de troca aniônica e no lado onde se encontra o cátodo, usa-se uma membrana catiônica. Quando uma corrente direta é aplicada ao sistema, íons (incluindo íons de metais pesados) irão se mover no campo elétrico de acordo com sua carga. As membranas de troca iônica garantem eficiência no fluxo por não permitir que os íons sejam transportados de um eletrólito para o outro, mas somente da madeira em direção ao eletrólito. O princípio de funcionamento do método de remediação pode ser modificado dependendo do tipo de material a ser remediado (Pedersen et al,. 2005).

Alguns parâmetros a serem otimizados neste tipo de processo incluem (Pedersen et al,. 2005).

- distância entre os eletrodos

- $\quad$ densidade de corrente;

- $\quad$ soluções de eletrólitos;

- $\quad$ dimensões das amostras; 
duração do tratamento.

Após a otimização dos referidos parâmetros, uma corrente elétrica de baixa voltagem é aplicada no sistema e, por meio desta, os íons na fase aquosa são forçados a migrar (incluindo metais pesados) para o campo elétrico, cada um em direção ao ânodo ou ao cátodo, dependendo da especiação. Como resultado, os íons são transportados para fora da madeira, indo diretamente para dentro do eletrólito nas unidades coletoras dos eletrodos (Pedersen et al,. 2005).

Pedersen et al. (2005) empregaram o método acima para remoção de $\mathrm{Cu}, \mathrm{Cr}$ e As de amostras de madeira tratada com CCA. Antes e após serem submetidos ao processo de remediação, os elementos em estudo foram quantificados por espectrometria de absorção atômica com chama (FAAS). Os resultados obtidos, em termos de eficiência de remoção, mostraram percentagens de $\mathrm{Cu}, \mathrm{Cr}$ e As na faixa de $88 \%$, $82 \%$ e $96 \%$, respectivamente.

\section{CONCLUSÕES}

No Brasil, até o presente momento, pouco interesse foi demonstrado em relação aos resíduos que são gerados após a vida útil de materiais confeccionados com madeira tratada com CCA. Entretanto, trabalhos de grupos diferentes (IPT e PUCRS) comprovaram a toxicidade dos resíduos de madeira tratada comercializada no país. Os estudos realizados por estes grupos seguiram a metodologia padrão de classificação de resíduos sólidos (ABNT 10004), mostrando que esses materiais não podem ser descartados da mesma forma que os demais resíduos, considerados não perigosos. Entretanto, por desconhecimento dos riscos, a maior parte dos usuários/consumidores não utiliza procedimentos adequados para o re-uso e disposição final desses resíduos. Desta forma, espera-se que o país siga a tendência mundial de restringir $o$ uso de preservativos a base principalmente de As e $\mathrm{Cr}$ e, adote normas severas de gestão dos resíduos gerados. Além disso, é extremamente necessário o investimento no desenvolvimento de metodologias seguras, economicamente viáveis e rápidas para a remoção dos elementos tóxicos desses resíduos uma vez que, o grande passivo ambiental relacionado aos resíduos existente, tende a aumentar significativamente no futuro devido à substituição mássica dos postes de madeira por postes de concreto.

\section{AGRADECIMENTOS}

À Coordenação de Aperfeiçoamento de Pessoal de Nível Superior - CAPES e a AES Sul Distribuidora Gaúcha S.A pelo apoio financeiro.

\section{REFERÊNCIAS}

2. Appel, J. S. L.; Terescova, V.; Rodrigues, V. C. B.; Vargas, V. M. F.; Rev. Bras. Toxicol. 2006, 19(1), 33.

3. Associação Brasileira de Normas Técnicas. NBR 10.004: Resíduos sólidos classificação. Rio de Janeiro: ABNT, 2004.

4. Associação Brasileira de Normas Técnicas. NBR 8456: Postes de eucalipto preservado para redes de distribuição de energia elétrica. Rio de Janeiro: ABNT, 1985.

5. Chang, Fang-Chih.; Wang, Ya-Nang,; Chen, Pin-Jui.; Ko, Chun-Han.; J. Environ. Manage. 2013, 122, 42.

6. Clausen, C. A.; Int. Biodeterior. Biodegrad.1996, 37(1-2), 101.

7. Clausen, C. A.; Kartal, S. N.; Muehl, J.; For. Prod. J. 2001, 51(7-8), 61.

8. Conselho Brasileiro de Construção Sustentável, Proposta de correção da Resolução CONAMA 307 referente à reclassificação da madeira industrializada, São Paulo, 2009.

9. Conselho Nacional do Meio Ambiente. Resolução 307: gestão dos resíduos da construção civil. Brasília, 2002.

10. Cooper, P. A.; and Associates, 2001. Analysis of consumer lumber waste management options. Final report prepared for Wood Preservation Strategic Options Process, Manufacturers/Treaters Steering Committee and Consumer Waste Lumber Working Group.

11. Coudert, L.; Blais, Jean-François.; Mercier, G.; Cooper, P.; Janin, A.; Gastonguay, L.; J. Environ. Manage. 2014, 132, 197.

12. Cruz, M. A. O.; Dissertação de Mestrado, Pontifícia Universidade Católica do Rio Grande do Sul, Brasil, 2011. 
13. Ferrarini, S. F.; dos Santos, H. S.; Miranda, L. G.; Azevedo, C. M. N.; Pires, M.; Maia, S. M.; Quím. Nova. 2012, 35, 1767.

14. Ferrarini, S. F.; Tese de Doutorado, Pontifícia Universidade Católica do Rio Grande do Sul, Brasil, 2012.

15. Hamula, C.; Wang, Z.; Zhang, H.; Kwon, E.; Li, X. F.; Gabos, S.; Le, X. C.; Environ. Health Perspect. 2006, 114(3), 460.

16. Helsen, L.; Van den Bulk, E.; Environ. Pollut. (Oxford, U. K.). 2005, 134(2), 301.

17. Hemond, H. E.; Solo-Gabriele, H. M.; Risk Analysis. 2004, 24(1), 51.

18. Hirata, T.; Inoue, M.; Fukui, Y.; Wood Sci. Technol. 1993, 27(1), 35.

19. http://www.chartherm.com/english/ chartherm/index.html, acessada em Outubro 2013.

20. http://www.tclmouroes.com.br, acessada em Janeiro 2014

21. http://www.twbrazil.com.br/artigostecnicos.ph p, acessada em Fevereiro 2014.

22. Humar, M.; Pohleven, F.; Sentjure, M.; Wood Science Technology. 2004, 37(6), 463.

23. Isosaari, P.; Marjavaara, P.; Lehmus, E.; J. Hazard. Mater. 2010, 182, 869.

24. Jang, Y. C.; Townsend, T. G.; Ward, M.; Bitton, G.; Bull. Environ. Contam. Toxicol. 2002, 69(6), 808.

25. Janin, A.; Blais, J. F.; Mercier, G.; Drogui, P.; J. Hazard. Mater. 2009a, 169(1), 136.

26. Janin, A.; Blais, Jean-François.; M.ASCE.; Mercier, G.; Drogui, P.; Kervella, H.; J. Environ. Eng. 2012c, 138, 200.

27. Janin, A.; Blais, Jean-François.; Mercier, G.; Drogui, P. J. Hazard. Mater. 2009c, 169, 1099.

28. Janin, A.; Coudert, L.; Blais, Jean-François.; Mercier, G.; Cooper, P.; Gastonguay, L.; Morris, P. Sep. Purif. Technol. 2012a, 85, 90.

29. Janin, A.; Coudert, L.; Riche, P.; Mercier, G.; Cooper, P.; Blais, Jean-François.; J. Hazard. Mater. 2011, 186, 1880.

30. Janin, A.; Riche, P.; Blais, Jean-François.; Mercier, G.; Cooper, P.; Morris, P.; Environ. Technol. 2012b, 33(18), 2111.

31. Janin, A.; Zaviska, F.; Drogui, P.; Blais, JeanFrançois.; Mercier, G. Hydrometallurgy. 2009b, 96, 318.

32. Kakitani, T.; Hata, T.; Kajimoto, T.; Ymamura, Y. J.; Environ. Qual. 2006, 35(3), 912.
33. Kartal, S. N.; Imamura, Y.; Bioresour. Technol. 2005, 96(3), 389.

34. Kartal, S. N.; Katsumata, N.; Imamura, Y.; For. Prod. J. 2006, 56(9), 33.

35. Kartal, S. N.; Kose, C.; Holz Roh- Werkst. (1937-2008). 2003, 61(5), 382.

36. Kartal, S. N.; Waste Manage. (Oxford, U. K.). 2003, 23(6), 537.

37. Kin, Y. S.; Kin, Singh, A. P.; lawa Journal. 2000, 21(2), 135.

38. Kwon, E.; Zhang, H.; Wang, Z.; Lu, X.; Jhangri, G. S.; Fok, N.; Gabos, S.; Li, X. F.; Le, X. C.; Environ. Health Perspect. 2004, 112(14), 1375.

39. Lelis, A. T. Biodeterioração de madeiras em edificações. Instituto de Pesquisa Tecnológica, IPT: São Paulo, 2001.

40. Lepage, E. Informativo Técnico: destinação final de madeira tratada com CCA. São Paulo, 2010. Disponível em: http://www.montana.com.br/Comunicacao/Pu blicacoes/Informativo-Tecnico. Acesso Maio 2014.

41. Lepage, E. S. Manual de Preservação de Madeiras: Vol. I e II. IPT - Divisão de Madeiras: São Paulo, 1986.

42. Moghaddam, A. H.; Mulligan, C. N.; Waste Manage. 2008, 28(3), 628.

43. Moreschi, J. C.; Rocha, M. P.; Borges, C. C.; Carvalho, R. C.; Revista da Madeira. 2002, 68, (ano 12).

44. Papassiopi, N.; Tambouris, S.; Kontropoulos, A.; Water, Air, Soil Pollut. 1999, 109(1), 1.

45. Pedersen, A. J.; Kristensen, I. V.; Ottosen, L. M.; Ribeiro, A. B.; Villumsen, A.; Eng. Geol. (Amsterdam, Neth.). 2005, 77(3-4), 331.

46. Reed, K.; Jimenez, M.; Freeman, N. C. G.; Lioy, P. J.; J. Exposure Anal. Environ. Epidemiol. 1999, 9(5), 513.

47. Shiau, R. J.; Smith, R. L.; Avellar, B.; Wood Sci. Technol. 2000, 34(5), 377.

48. Sierra-Alvarez, R.; Waste Manage. (Oxford, U. K.). 2009, 29(6), 1885.

49. Silva, G. A.; Dissertação de Mestrado, Instituto de Pesquisas Tecnológicas do Estado de São Paulo, Brasil, 2008.

50. Silva, J. C.; Revista da Madeira. 2006, 16 (ano 100).

51. Solo-Gabriele, H. M.; Townsend, T.; Waste Manage. Res. 1999, 17(5), 378.

52. Thomas, R. A. P.; Lawlor, K.; Bailey, M.; Macaskie, L. E.; Appl. Environ. Microbiol. 1998, 64(4), 1319.

53. Vidor, F. L. R.; Dissertação de Mestrado, 
Pontifícia Universidade Católica do Rio

Tokunaga.; Water, Air, Soil Pollut. 2001, Grande do Sul, Brasil, 2003.

54. Wasay, S. A.; Wasay, S.; Barrington, S. 127(1-4), 301.

PERIÓDICO TCHÊ QUÍMICA • www.periodico.tchequimica.com • Vol. 12 N. 23.

• ISSN 1806-0374 (impresso) • ISSN 1806-9827 (CD-ROM) • ISSN 2179-0302 (meio eletrônico)

(C) 2015. Porto Alegre, RS. Brasil

The Periódico Tchê Química (ISSN: 1806-0374; 2179-0302) is an open-access journal since 2004. Journal DOI: 10.52571/PTQ. http://www.tchequimica.com. This text was introduced in this file in 2021 for compliance reasons.

() The Author(s)
OPEN ACCESS. This article is licensed under a Creative Commons Attribution 4.0 (CC BY 4.0) International License, which permits use, sharing, adaptation, distribution, and reproduction in any medium or format, as long as you give appropriate credit to the original author(s) and the source, provide a link to the Creative Commons license, and indicate if changes were made. The images or other third-party material in this article are included in the or exceeds the permitted use, you will need to obtain permission directly from the copyright holder. To view a copy of this license, visit http://creativecommons.org/licenses/by/4.0/. 